\title{
A COMPETÊNCIA EM TECNOLOGIA PARA A SALA DE AULA: QUEM APRENDE PARA ENSINAR?
}

\author{
Maria Lúcia Dias* \\ Maria do Rocio Fontoura Teixeira**
}

Resumo: Este trabalho retoma um dos temas tratados em pesquisa de Doutorado, que buscou verificar o perfil de competência adquirida durante a formação de professores egressos dos cursos de Licenciatura em Biologia, Física e Química da Universidade Federal do Rio Grande do Sul, no uso de Tecnologias Digitais de Informação e Comunicação. São disciplinas que apresentam dificuldades aos alunos em função da sua complexidade. Assim, acredita-se que o professor que tiver a competência necessária no uso daquelas tecnologias poderá interagir com os alunos num ambiente tecnológico, que lhes é conhecido e familiar. Alguns resultados da pesquisa empírica realizada junto aos formandos são mostrados. As abordagens teóricas tratam da mudança necessária de paradigmas e atitudes no cenário de ensino e da aprendizagem no século XXI, para a era digital em que vivemos.

Palavras-chave: Tecnologia na Educação. Formação de professores. Teorias educacionais aplicadas às Tecnologias Digitais de Informação e Comunicação.

\section{Introdução}

Este trabalho traz os resultados iniciais da pesquisa empírica que buscou identificar o perfil de competência adquirida durante a formação de professores egressos dos cursos de Licenciatura em Biologia, Física e Química da Universidade Federal do Rio Grande do Sul (UFRGS), no uso de Tecnologias Digitais de Informação e Comunicação (TDIC). O perfil dos egressos no uso da tecnologia é um dos objetivos específicos da pesquisa de Doutorado que foi realizada durante o período de 2017/2 e 2018/1. Os egressos das Licenciaturas, sujeitos da pesquisa, são os indivíduos que ensinarão disciplinas que apresentam várias dificuldades aos alunos, em função da sua complexidade, as quais, muitas vezes, chegam a gerar questionamentos acerca da utilidade de seus conteúdos no cotidiano dos alunos. As utilizações em sala de aula do ambiente tecnológico, no qual crianças e adolescentes desta era digital estão inseridos, têm mostrado bons resultados na aceitação dos conteúdos, e sua compreensão, de acordo com os autores que se dedicam a estudá-los.

\footnotetext{
* Doutoranda no Programa de Pós-Graduação de Educação em Ciências: Química da Vida e Saúde da Universidade Federal do Rio Grande do Sul. Mestre em Educação pelo UNILASALLE, Canoas, RS.

**Doutora pelo Programa de Educação em Ciências: Química da Vida e Saúde da Universidade Federal do Rio Grande do Sul. Possui Mestrado em Administração pela mesma universidade.
} 
Assim, acredita-se que o professor que tiver a competência necessária no uso das TDIC poderá interagir com resultados bastante positivos com os alunos naquele ambiente, que lhes é conhecido e familiar, o que pode tornar o aprendizado mais lúdico e próximo do contexto em que os alunos vivem. O professor, como mediador em sala de aula entre o conhecimento e o aluno, pode, e deve desenvolver esta função primordial através de novas competências que ajustem seu desempenho às inovações, por isso é tão importante que a competência necessária seja adquirida a partir da formação, inicial ou continuada, dos futuros professores.

Devem ser consideradas, evidentemente, as competências já adquiridas em outros momentos anteriores ao ingresso nos cursos de Licenciatura. Mas, o foco desta pesquisa foi identificá-las neste momento da vida acadêmica dos sujeitos, quando já são, praticamente, egressos de cursos de Licenciaturas na área das Ciências e, no caso, em estágios de docência. A partir da pesquisa empírica, obtiveram-se resultados que serão mostrados, analisados utilizando-se a metodologia da Análise Textual Discursiva (ATD).

Abordagens teóricas em relação ao ato de ensinar e aprender no mundo digital também são apresentadas. Essas abordagens tratam da mudança necessária de paradigmas e atitudes no cenário de ensino/aprendizagem no século XXI. Entre as mudanças, pode-se considerar o uso da Aprendizagem Móvel, tratada ao final da próxima seção, como uma importante ferramenta.

\section{Três teorias sobre as Tecnologias Digitais de Informação e de Comunicação na Educação}

Pierre Lévy (1999) abordou o ato de ensinar e aprender no mundo digital, quando concebeu a ideia de Cibercultura como um espaço de inovações que traria mudanças de paradigmas em relação à Educação. Segundo ele, a velocidade da renovação de saberes, a nova natureza do trabalho e a amplificação, exteriorização e modificação de inúmeras funções cognitivas do ser humano, são variáveis sem as quais não é mais possível pensar em Educação no espaço da Cibercultura.

O ensino e a aprendizagem devem levar em conta as "tecnologias intelectuais" que favoreceriam "novas formas de acesso à informação" e "novos estilos de raciocínio e de conhecimento" (LÉVY, 1999, p.157). Lévy discorreu sobre as reformas necessárias nos sistemas de educação e formação desde então, quando do lançamento do original do livro Cibercultura em 1997. Nele, o autor identificou a necessidade de "um novo estilo de 
Pedagogia, que favorece ao mesmo tempo as aprendizagens personalizadas e a aprendizagem coletiva em rede" (LÉVY, 1999, p.158). Disse que "nesse contexto, o professor é incentivado a tornar-se um animador da inteligência coletiva de seus grupos de alunos em vez de um fornecedor direto de conhecimentos" (LÉVY, 1999, p.158).

Hoje, por exemplo, quando se presencia o papel fundamental que a Educação a Distância (EAD) desempenha na vida de milhões de pessoas, e as oportunidades que são oferecidas aos profissionais das mais variadas áreas de conhecimento, nos diferentes níveis, através de sua utilização, para a formação inicial ou continuada, constata-se que essa realidade não seria possível sem a devida qualificação e capacitação dos professores envolvidos.

Ainda sobre a capacitação dos professores, para o uso das ferramentas digitais com os alunos, em uma entrevista de 2014, o autor afirmou:

Sou a favor da adoção dessas tecnologias, como os tablets, mas isso não resolve os problemas. Se os professores não forem, eles mesmos, muito bons em usar essas ferramentas, no sentido de usar para aprender, para explorar, colaborar e tudo mais, não vai ser válido. Só tablets não fazem o trabalho sozinhos. Só a ferramenta não resolve, se você não sabe usar (LÉVY, 2014, p.1).

Naquele momento, sobre o uso das redes sociais, apenas como exemplo, o ponto de vista do autor foi além do uso comum. Segundo ele,

Na nova mídia, você não aprende lendo o texto. Aprende junto: se comunicando, com exploração ativa, comparando fontes... Se os professores não usarem essa nova mídia para si mesmos, nunca serão capazes de ensinar os alunos a usar essas ferramentas. Os estudantes já sabem usar as redes sociais para trocar vídeos de gatinhos, para diversão ou videogames estúpidos. Agora, têm que aprender a escolher jogos interessantes e sérios. Entender o processo de aprendizado coletivo e filtragem de dados (LÉVY, 2014, p.1).

Em outra entrevista, Lévy (2012) abordou várias outras questões sobre as ferramentas digitais para a Educação. Entre elas a 'gestão da atenção', tão discutida entre os professores em geral. Mesmo com outras nomenclaturas, trata-se de uma mesma situação, ou seja, o uso de dispositivos móveis digitais em sala de aula dispersa/desconcentra, os alunos? O professor tem que limitar o seu uso ou simplesmente proibir? Na segunda opção, será possível, nos dias atuais, simplesmente abolir tais recursos para o ensino e a aprendizagem? Lévy explica que "a gestão da atenção não é algo que começou com as ferramentas digitais, disciplina mental, aprender a concentrar-se, é algo que sempre foi útil e que deve também ser aplicado com essas ferramentas" (LÉVY, 2012, p.1). Muitos professores discutem certo déficit de atenção dos alunos em salas de aula. Constata-se, diariamente, a dificuldade de manter uma classe realmente atenta ao que está sendo discutido na temática das aulas. Na maioria das vezes, as 
leituras recomendadas não são feitas porque exige concentração, disponibilidade de tempo, entendimento, compreensão. É considerado trabalhoso e aborrecido para a maioria dos alunos.

Lévy (2012) afirmou sobre o aspecto “disciplina mental” que, segundo ele, deverá ser uma das habilidades dos alunos do futuro, aumentando sua própria produtividade e a otimização do tempo:

A sobrecarga cognitiva é realmente um problema falso porque é o mesmo que dizer que há livros demais em uma biblioteca. Muitos livros não provocam uma sobrecarga cognitiva, [...] você aprende a escolher um livro mais adequado com o seu objetivo e lê esse livro, não começa a ler a primeira página, depois busca outro livro. [...] É um domínio de si próprio, uma disciplina. E essa disciplina já tem que ser ensinada durante a escola primária. (LÉVY, 2012, p.1).

Quanto à orientação aos alunos pelos professores, ele afirma que "os professores devem ensinar sobre a responsabilidade social para a memória coletiva porque a própria Internet contribui para uma memória coletiva" (LÉVY, 2012, p.1). Destaca a importância de se ter espírito crítico, sabendo separar fontes boas de fontes ruins, aprendendo a transformar informação em conhecimento, a partir de uma orientação efetiva.

Juan Manuel Moran, na teoria da Educação Inovadora, proposta por ele e também chamada de Ensino Híbrido, enfatizou a mudança necessária de paradigmas no ensino/aprendizagem no séc. XXI. Em uma palestra de 1999, sobre mudanças que estavam por vir no ensino, afirmou que "ensinar com as novas mídias será uma revolução se mudarmos, simultaneamente, os paradigmas convencionais do ensino, que mantêm distantes professores e alunos" (MORAN, 1999, p.2).

Segundo ele, sem uma mudança significativa na metodologia, "conseguiremos dar um verniz de modernidade, sem mexer no essencial" (MORAN, 1999, p.2). Afirmou que "a Internet é um novo meio de comunicação, ainda incipiente [sic], mas que pode nos ajudar a rever, a ampliar e a modificar muitas das formas atuais de ensinar e de aprender" (MORAN, 1999, p.2). Alguns elementos do ensino, como o currículo, as metodologias, além de tempos e espaços de ensino, precisariam ser revistos por gestores educacionais e professores. Faz-se necessário aprender a lidar com a informação e a construir conhecimento de novas formas.

Em um dos seus últimos livros, o autor retoma a importância que sempre atribuiu à Internet e às tecnologias na Educação:

A Internet e as tecnologias móveis trazem desafios fascinantes, ampliando as possibilidades e os problemas, num mundo cada vez mais complexo e interconectado, que sinaliza mudanças muito profundas na forma de ensinar e 
aprender, formal e informalmente, ao longo de uma vida cada vez mais longa (MORAN, 2015a, p.71).

Moran afirma que é possível mudar e inovar em Educação. O processo não precisa, nem deve ser lento demais, e pode iniciar com pequenas mudanças nas atitudes dos professores na interação e mediação em sala de aula com os alunos. Corroborando sua própria visão de Escola Inovadora, baseada na presença insubstituível da tecnologia, o autor revela diferentes concepções de inovações na Educação, as quais ele denomina de "diferenciais" que, de acordo com a política escolar de cada situação e local, vão se identificando em busca de um resultado inovador. O autor afirma que esses "diferenciais" podem ser agrupados em:

1. Ambientes institucionais acolhedores e de incentivo à experimentação; 2 . Currículos transdisciplinares, personalizados, híbridos; 3. Metodologias ativas; 4. Tecnologias digitais integradas; 5. Integração profunda com a cidade e com o mundo: aprendizagem/serviço; 6. Professores orientadores e mentores; e 7. Novas formas de avaliação e certificação. (MORAN, 2013, p.1)

Em sua concepção, o ensino híbrido, também considerado uma inovação educacional do seu ponto de vista, é uma mistura de diferentes formas de ensinar e aprender, onde três processos devem ser apresentados e agir juntos na sala de aula, de forma presencial ou digital, levando ao caminho do aprendizado, com maior ou menor supervisão, desta forma aperfeiçoando a aprendizagem. Estes processos de ensinar e aprender podem ser integrados e combinados, conforme expõe:

\begin{abstract}
A aprendizagem individual: cada um pode aprender o básico por si mesmo (aprendizagem prévia, aula invertida), com pouca interferência direta do professor; aprendemos mais uns com os outros (aprendizagem entre pares, através de diferentes atividades, grupos, redes); e a aprendizagem mediada por pessoas mais experientes (professores, orientadores, mentores). (MORAN, 2015, p.1)
\end{abstract}

Já o Conectivismo, proposto por George Siemens em 2004, é considerado outra nova Teoria de Aprendizagem que também traz a ideia de redes, de conexões, para a aprendizagem, ou seja, a aprendizagem na Sociedade da Informação não é mais um construto individual, mas deve ser coletivo, grupal, significativo. De acordo com Siemens(2004, p.1), "as teorias de aprendizagem existentes eram insuficientes para compreender as características do indivíduo aprendiz do século XXI face às novas realidades do nível do desenvolvimento tecnológico e da sociedade".

A tentativa natural dos teóricos é continuar a revisar e desenvolver as teorias na medida em que as condições mudam. Em algum ponto, no entanto, as condições subjacentes se alteraram tão significativamente, que as modificações posteriores não são mais perceptíveis. Conforme Siemens, “é necessária uma abordagem inteiramente nova” (2004, p.1). 
Algumas tendências da aprendizagem, neste momento, devem ser levadas em conta, de acordo com o autor. Entre elas, destacam-se: a aprendizagem informal que acontece através de comunidades de prática, redes pessoais e conclusão de tarefas relacionadas ao trabalho. Uma vez que a educação formal já não dá conta do processo de aprendizagem individual, a forma de pensar, raciocinar e assimilar informações está sendo alterada/reestruturada pela tecnologia. Os recursos tecnológicos disponíveis hoje definem, moldam, organizam um novo modo de pensar e agir e os processos cognitivos de informações, tratados antes pelas teorias de aprendizagem, hoje podem ser tratados/suportados pela Tecnologia. De acordo com Siemens (2004, p.1), "saber onde" encontrar a Informação para construir o Conhecimento, tem papel mais relevante do que "saber como" ou "saber o que".

Siemens menciona que, entre as várias questões que podem ser exploradas em relação às teorias de aprendizagem existentes, uma delas merece destaque pelo contexto atual, com relação ao impacto da tecnologia: qual o ajuste é necessário fazer nas teorias da aprendizagem quando a tecnologia realiza muitas das operações cognitivas anteriormente realizadas pelos aprendizes (armazenamento e recuperação de informação)? As conexões que capacitam a aprender cada vez mais são mais importantes que o estado atual de Conhecimento, e a aprendizagem está focada em conectar conjuntos de informações especializadas para responder às questões propostas e que podem estar fora do conhecimento de cada um, como numa base de dados ou numa organização, por exemplo.

Siemens apresenta também os oito princípios do Conectivismo, alguns dos quais se destacam por sua relevância no contexto deste trabalho:

\footnotetext{
Aprendizagem é um processo de conectar nós especializados ou fontes de informação, a habilidade de enxergar conexões entre áreas, ideias e conceitos é uma habilidade fundamental, atualização ("currency" - conhecimento acurado e em dia) é a intenção de todas as atividades de aprendizagem conectivista, a análise das redes sociais é um elemento adicional na compreensão dos modelos de aprendizagem na era digital. (SIEMENS, 2004, p.6).
}

O Conectivismo parte do indivíduo e de seu conhecimento pessoal, composto por uma rede que subsidia as organizações e as instituições de informações, que retornam com outras informações à rede e, assim, provê a aprendizagem ao indivíduo: "Essa amplificação da aprendizagem, conhecimento e compreensão através da extensão de uma rede pessoal é a síntese do Conectivismo" (SIEMENS, 2004, p.7). A necessidade de rápidas respostas às várias demandas que se apresentam na vida cotidiana, seja de profissionais ou de aprendizes, é uma 
das situações previstas pelo Conectivismo. Em muitos casos, são respostas que vêm de redes sociais ou pessoais, num processo de retroalimentação individual ou coletiva, e simultânea.

Ao encontro das teorias, as ferramentas digitais a serem utilizadas são fundamentais para possibilitar a criação de novos ambientes de ensino-aprendizagem. Atualmente, vários softwares e aplicativos educacionais podem ser instalados nos computadores dos laboratórios escolares ou em casa, em tablets, notebooks ou em smartphones, nem sempre sendo necessário o acesso à Internet. A Aprendizagem Móvel já se constitui uma possibilidade concreta de interação professor/alunos/conteúdos. Em relação a essa ferramenta digital, a UNESCO [201-?] trabalha no sentido de identificar na Aprendizagem Móvel uma solução para o enfrentamento de muitos dos desafios tecnológicos mundiais na área da Educação, principalmente em países com pouca estrutura tecnológica de base. Segundo o Relatório de Monitoramento Global 2015 da UNESCO “as tecnologias móveis têm a chave para transformar a exclusão digital que existe atualmente, em dividendos digitais, trazendo educação igualitária e de qualidade para todos" ([201-?]a, p.3). Na pesquisa documental sobre o assunto, viu-se que esta é uma realidade brasileira também (UNESCO, [201-?]b).

Ainda em relação às ferramentas digitais e seu uso na Educação, no Encontro Internacional Educação 360 (TECNOLOGIA..., 2016), um debate reuniu vários especialistas em Educação e tecnologias, onde os mesmos discutiram e se posicionaram positivamente quanto ao que foi apresentado e está sendo utilizado neste momento. Naquele debate durante o evento, foram apresentados três estudos de caso, demonstrando, na prática, que a tecnologia deve estar presente na sala de aula como apoio às atividades propostas pelo professor, e como isso está sendo realizado. Um dos casos apresentados foi o da Plataforma Faz Sentido, que disponibiliza na rede 120 práticas inovadoras para o Ensino Médio; outro caso apresentado foi de uma experiência que investe na formação de professores para o Ensino Híbrido, onde o formato tradicional é compartilhado com a aplicação de vídeo-aulas e que inclui o uso de dispositivos móveis como smartphones e tablets em sala; o terceiro caso foi sobre o uso de softwares educacionais livres para dispositivos móveis no mesmo formato do Wikipedia, que lista mais de 300 softwares livres para serem baixados e acessados por qualquer pessoa. Segundo David Cavallo, presente ao debate e referência mundial no uso de tecnologia na Educação, será impossível oferecer uma Educação de qualidade em escala nacional sem tecnologia, principalmente considerando-se a expansão territorial do Brasil. 
A intenção, ao trazer as ideias desses autores, é de que sirvam para que se faça uma reflexão do que já é possível realizar, a partir do uso das tecnologias digitais pelos professores e alunos em sala de aula.

\section{Metodologia da pesquisa}

Conforme apresentado na Introdução, a pesquisa empírica realizada teve como objetivo identificar o perfil de competência adquirida durante a formação de professores formandos dos cursos de Licenciatura em Biologia, Física e Química da Universidade Federal do Rio Grande do Sul no uso de Tecnologias Digitais de Informação e Comunicação. Trata-se de uma pesquisa qualitativa e investigativa, realizada no período de 2017/2 e 2018/1, onde foram propostas quatro perguntas abertas num questionário aplicado aos sujeitos, Quadro 1, pessoalmente, em sala de aula pela pesquisadora.

Quadro 1 - Perguntas apresentadas no questionário

1 Você já tinha conhecimentos prévios sobre o uso de tecnologias no ensino antes de ingressar no curso escolhido? Em caso positivo, qual conhecimento você já possuía?

2 Do seu ponto de vista, você agregou competências para o uso de Tecnologias Digitais de Informação e Comunicação no ensino, durante a sua formação? Alguma disciplina específica?

3 Em caso positivo, quais foram as competências agregadas à sua formação para o uso das Tecnologias Digitais de Informação e Comunicação no ensino?

4 Quanto à utilização efetiva das competências para o uso de Tecnologias Digitais de Informação e Comunicação no ensino durante a sua formação, qual(is) você pretende implementar com seus alunos em sala de aula?

Fonte: Elaborado pelas autoras

As respostas ao questionário foram analisadas a partir da metodologia de Análise Textual Discursiva (ATD). A metodologia escolhida foi conhecida a partir de disciplina oferecida durante o curso e considerada apropriada para os objetivos do trabalho, uma vez que,

A ATD, inserida no movimento da pesquisa qualitativa não pretende testar hipóteses para comprová-las ou refutá-las ao final da pesquisa; a intenção é a compreensão, a reconstrução de conhecimentos existentes sobre os temas investigados (MORAES; GALIAZZI, 2013, p.33). 
Afinal, tão importante quanto os dados coletados, a compreensão dos fatos, opiniões, sentimentos e pontos de vista dos sujeitos, devem ser o foco da pesquisa para que seus resultados mostrem, com fidelidade, um recorte da realidade pesquisada e para que a pesquisa possa ser considerada bem-sucedida. A ATD, através das etapas a seguir descritas, estabelece a relação necessária entre o pesquisador e o sujeito:

1. Unitarização com o exame dos textos em detalhes e a posterior produção de unidades constituintes de sentido referentes aos fatos estudados; 2. Categorização com a construção de relações entre as unidades de respostas a partir de conteúdos similares; 3. Nova compreensão do todo com a crítica e validação da nova compreensão, com a construção de um metatexto como resultado do processo para explicitar a compreensão possível das duas etapas anteriores; e 4. A partir da autoorganização da compreensão elaborada pelo pesquisador, obtêm-se os resultados (imprevisibilidade) (MORAES; GALIAZZI, 2013, p.36).

Neste trabalho procurou-se trazer os resultados obtidos, a partir da unitarização inicial e posterior simplificação do processo de análise. Foram elaborados quadros com as respostas conforme o modelo abaixo, Quadro 2, para cada uma das respostas, a cada questão, de cada grupo de sujeitos.

Quadro 2 - Modelo de tabela para análise das respostas e categorização

\begin{tabular}{|l|c|l|c|l|}
\hline SUJEITO & UNIDADES & REESCRITA & SUBCATEGORI & CATEGORIAS \\
DE SENTIDO & DA UNIDADE & AS & \\
\hline & & & & \\
\hline
\end{tabular}

Fonte: Ribeiro, 2018.

Para demonstrar a dinâmica da ATD, a partir da tabela elaborada, inicia-se com a transcrição das respostas dos questionários na coluna das Unidades de Sentido, que passa a ser o "corpus" da ATD: A Análise Textual Discursiva concretiza-se a partir de um conjunto de documentos denominado corpus. Esse representa as informações da pesquisa e "[...] requer uma seleção e delimitação rigorosa" (MORAES; GALIAZZI, 2013, p.38).

A partir da análise dos temas/pontos mais relevantes da leitura e compreensão das respostas, há o exame dos textos e a identificação das expressões e palavras que dão sentido à resposta obtida, quando se elabora a Reescrita da unidade. A partir daí, é possível eleger algumas subcategorias que constituirão o metatexto daquela unidade (resposta). Finalmente, verificando os sentidos similares, palavras e termos presentes de forma característica nas 
unidades (respostas), pode-se determinar o sentido mais próximo que levará à categoria final daquela resposta. As categorias podem ser previamente determinadas pelo pesquisador de forma que atenda às perguntas que foram feitas aos sujeitos.

\footnotetext{
Os textos são assumidos como significantes em relação aos quais é possível exprimir sentidos simbólicos. Pretende-se, assim, construir compreensões a partir de um conjunto de textos, analisando-os e expressando, a partir da análise, os sentidos e significados possíveis. (MORAES; GALIAZZI, 2013, p.36)
}

As quatro perguntas foram elaboradas com o objetivo de identificar, junto aos sujeitos, seus conhecimentos prévios, aplicabilidade e perspectivas de uso das TDIC, durante e a partir da sua formação como professores de Biologia, Física e Química na Universidade Federal do Rio Grande do Sul (UFRGS). Cada turma tem uma previsão do número de alunos formandos no semestre, mas, normalmente, por várias razões, nem todos se formam no tempo previsto, mesmo assim, podem-se constatar grupos com boa representatividade para a pesquisa. $\mathrm{O}$ questionário foi aplicado em sala de aula com a autorização e na presença do professor responsável pelas disciplinas de Estágio Docente I ou II, momento final de conclusão dos cursos e poucos sujeitos não estavam presentes no dia em o questionário foi aplicado. Entre os formandos dos três cursos, totalizou-se 51 formandos. Destes, 36 responderam o questionário proposto, totalizando $70,5 \%$ do total.

\section{Análise dos dados da pesquisa}

A primeira questão, que tratou sobre os conhecimentos prévios dos sujeitos sobre o uso de tecnologias digitais de informação e comunicação (TDIC) no ensino, antes de ingressar no curso escolhido, obteve do total de 36, 14 respostas positivas e 22 negativas. Os que responderam positivamente apontaram como conhecimentos prévios, basicamente, o uso de aplicativos do pacote Office, da Microsoft, e também o uso de Datashow no Ensino Médio, vídeos em sala de aula, uso de redes sociais para estudos, e um dos sujeitos, apontou o uso software Autocad.

À segunda questão, que tratou das competências agregadas durante os cursos para o uso de TDIC no ensino, 23 sujeitos informaram que agregaram alguma competência e 13 responderam que não agregaram competências para esta tarefa. 
No caso do curso de Biologia, especificamente, dos oito sujeitos que responderam afirmativamente às questões um e dois, notou-se respostas bem diferentes, mesmo em se tratando da mesma formação e currículo. Isso demonstra que as competências agregadas, o foram muito mais em função do interesse pessoal de cada um em conhecer tecnologias disponíveis durante o curso, do que da obrigatoriedade de aquisição das mesmas para a formação, ou, ainda, do oferecimento de disciplinas obrigatórias no currículo do curso. A disciplina "Ecologia de populações e comunidades II", na qual foi utilizado um simulador educacional específico, foi a única apontada por um único sujeito. No curso de Química, das 9 respostas positivas, 8 sujeitos apontaram disciplinas oferecidas pela Faculdade de Educação (FACED) da UFRGS, não específicas ao curso de Química. O único sujeito que apontou uma disciplina específica do curso citou a disciplina Físico-Química III.

Pode-se observar que, em relação às duas primeiras questões, os formandos do curso de Física demonstraram uma realidade um pouco diferente. Dos sete sujeitos que responderam o questionário, seis afirmaram que agregaram competências para o uso das TDIC no ensino, a partir da sua formação durante o curso. E mesmo o único sujeito que informou que não agregou competência, justificou sua negativa explicando que, a seu ver, os conteúdos da disciplina que cursou estavam ultrapassados, defasados, mas não a identificou. As disciplinas específicas apontadas pelos outros seis sujeitos foram: Métodos computacionais para a Licenciatura A e B e Pesquisa em ensino de Física.

A questão três, que procurou identificar quais competências foram agregadas para o uso das TDIC durante a formação, obteve 17 respostas positivas dos sujeitos dos cursos de Biologia e Química, os quais informaram que as competências foram agregadas informalmente, por exemplo, na relação entre colegas ou em eventos dos quais participaram. Ou seja, nada efetivo em relação às disciplinas dos currículos propriamente. Foram citadas competências para uso de vídeos, incluindo sua elaboração, para uso de simuladores educacionais, para uso de softwares educativos, jogos educacionais e uso de sites especializados e bancos de dados em Química.

Após a análise e categorização das respostas, entendeu-se que, das 17 respostas positivas, todas levam à categoria definida como competência restrita agregada durante os cursos. Como competência restrita se considerou aquela competência que não foi agregada formalmente durante a formação na Universidade, a partir das disciplinas do currículo. É uma 
competência de uso pontual e/ou foi adquirida através de informações entre colegas e/ou em alguma apresentação/evento extraclasse.

Diferentemente do que foi percebido nos cursos de Biologia e Química, os formandos do curso de Física responderam à questão três, que procurou identificar quais competências foram agregadas para o uso das TDIC durante a formação, com seis respostas afirmativas e uma negativa e, quanto às competências agregadas, citaram: recursos digitais para a elaboração de aulas interativas, programação para gerenciamento de plataforma digital e também criação de sites. Além de citarem também as competências necessárias para o uso de vídeos e uso de softwares de simulação.

Após a análise e categorização das respostas, identificou-se no curso de Física a categoria de competência ampla, onde o conteúdo aprendido durante a formação deu aos sujeitos a possibilidade de adquirir competência no uso das TDIC no ensino, de forma não restrita ao uso comum, ou leigo. Foi possível identificar o uso das TDIC de forma específica para o ensino de Física.

$\mathrm{Na}$ quarta e última questão, os sujeitos responderam sobre quais as competências agregadas, durante a formação, seriam implementadas para uso efetivo das TDIC em sala de aula com seus futuros alunos. Nos cursos de Biologia e Química, observou-se que, mesmo os 12 sujeitos que não reconheceram ter adquirido alguma competência durante a sua formação de acordo com os conteúdos curriculares, vivenciaram algumas experiências no uso das tecnologias, gostariam de ampliar este conhecimento, mesmo que informal, e levá-lo para a sala de aula. Mesmo vindo ao encontro das respostas da questão três e a identificação de uma competência restrita, observou-se que aqueles sujeitos reconhecem a importância do uso das TDIC em sala de aula com seus alunos. Mas, em função de não saberem usar ferramentas específicas relacionadas à sua formação, eles citam algumas ferramentas de âmbito geral como, por exemplo: aprendizagem móvel, com uso de celulares e tablets, Ambiente Virtual de Aprendizagem como o MOODLE, que conheceram em função do uso constante por professores da UFRGS, pesquisa dirigida na Internet (recomendadas por professores quando indicam temas ou textos disponíveis em sites na Internet para os alunos), compartilhamento de textos no Google Drive, e outras atividades gerais. O aprendizado para a utilização das ferramentas tecnológicas citadas foi construído aleatoriamente, com ajuda de colegas e/ou amigos, ou a partir das disciplinas cursadas na FACED/UFRGS e não nas disciplinas específicas dos cursos. 
Novamente, notou-se uma diferenciação em relação a esta questão de uso efetivo das TDIC em sala de aula pelos futuros professores de Física, uma vez que, como anteriormente, das sete respostas, seis sujeitos responderam negativamente quanto a ter conhecimentos prévios sobre o uso de TDIC no ensino antes de ingressar no curso escolhido. Reconheceram que agregaram competências para o uso efetivo das TDIC durante a formação e indicaram as disciplinas específicas do curso que lhes proporcionou esta condição. A partir disto, pode-se chegar á constatação de que houve uma apropriação de conhecimentos relativos ao uso das TDIC no ensino por estes sujeitos a partir de disciplinas específicas do curso, o que resultou na constatação de uma competência ampla agregada a sua formação que deverá ser colocada à disposição dos alunos em sala de aula. Algumas competências específicas citadas: para uso dos softwares Modelus, Plickers, softwares de simulação específicos e uso de ambientes virtuais aplicados à Física.

A partir da análise dos dados coletados, identificaram-se algumas inconsistências entre o que foi manifestado pelos sujeitos da pesquisa em comparação aos Projetos Pedagógicos dos Cursos (PPC), analisados na pesquisa documental da tese. Como exemplo, pode-se citar o que consta no PPC do curso de Licenciatura em Ciências Biológicas (Biologia), onde consta que "uma das finalidades explícitas do programa é ser uma ação de inclusão digital, viabilizando que os professores venham a serem proficientes nos códigos e linguagens das chamadas TICs" (UNIVERSIDADE..., 2016). O mesmo ocorreu em relação ao PPC do curso de Licenciatura em Química, onde está explícito que, entre as habilidades e competências que o estudante deverá desenvolver, uma delas seria "utilizar novas tecnologias da informação e comunicação como recurso didático para a busca de informações para a construção de conhecimento" (UNIVERSIDADE..., 2016).

Por outro lado, foi possível identificar coerência na análise que foi feita no PPC do curso de Licenciatura em Física, com o que foi manifestado pelos sujeitos pesquisados, uma vez que o mesmo recomenda que os egressos do curso devam apresentar "abertura para novas tecnologias disponíveis à prática educacional, com habilidade na utilização dos diversos recursos de informática, dispondo de conhecimento de linguagens computacionais[...]" (UNIVERSIDADE..., 2016). 


\section{Considerações finais}

$\mathrm{Na}$ análise dos resultados da pesquisa, a partir das respostas dos sujeitos, ficou evidente a necessidade de reflexão sobre a formação dos futuros professores de Física, Química e Biologia que está sendo construída atualmente na UFRGS. Além dos PPC, foram analisados os currículos e conteúdos de cerca de 590 disciplinas dos cursos pesquisados e pode-se afirmar que, teoricamente, os três cursos têm como objetivo a formação de um professor com embasamento teórico e prático para o ensino, onde o uso da tecnologia digital está presente. Esta constatação foi possível identificar tanto no uso de softwares ou aplicativos específicos enquanto ferramentas para resolução de problemas, citados nos conteúdos das disciplinas, quanto nos ambientes virtuais utilizados para as aulas. Através da pesquisa, podese constatar que, conforme o sujeito respondente existe uma lacuna significativa em relação a um conhecimento efetivo de tecnologias específicas a serem apresentadas nas diferentes disciplinas específicas dos cursos.

Muitos professores, com mais tempo de docência, formando professores no Ensino Superior, continuam com seus antigos hábitos de ensino, numa zona de conforto conhecida, como se pode observar na carência de disciplinas específicas, ou de conteúdos específicos nas disciplinas, para que o egresso realmente agregue competências efetivas para o uso e ensino das tecnologias digitais em sala de aula. Professores de áreas tão complexas construiriam uma maior e melhor interação com seus alunos a partir da linguagem compreendida pela geração dos "nativos digitais" (PRENSKY, 2001, p.2). A competência agregada qualificada no uso das TDIC pelos futuros professores auxiliaria os alunos a construir um conhecimento também qualificado em Física, Química e Biologia. Nas respostas à pesquisa, observou-se também que, mesmo professores em processo de formação justificam a não adoção da tecnologia em sala de aula devido à falta de estrutura mínima das escolas, condição econômica e/ou dificuldades de acesso à Internet pelos alunos e outros fatores. Na verdade, pode-se afirmar que nos dias de hoje é necessário preparar professores que ensinem voltados para o futuro, focados na aprendizagem efetiva dos alunos e desenvolvendo sua própria competência, não mais levando em consideração a realidade e limitações do passado. As exigências profissionais são cada vez maiores, mas possibilidades de capacitação e qualificação existem, e ferramentas também.

É necessário o olhar cuidadoso para os alunos que hoje fazem parte de outra realidade, têm mais informação e outra capacidade de avaliação, aprendizagem e criticidade. Não é mais possível apenas reclamar da estrutura ou do aluno, faz-se necessária a autocrítica para a 
proposta de novos métodos de ensino para o aluno de hoje, conectado e voltado às novidades tecnológicas. Os problemas existem, naturalmente, são conhecidos, mas soluções e iniciativas para enfrentá-los também estão disponíveis para todos aqueles que se dispuserem a mudar e inovar. Quanto à universidade, instituição formadora dos futuros profissionais, é fundamental que esteja preparada para a autocrítica necessária de métodos de ensino e para a avaliação do que e como está sendo ensinado. Professores são agentes de mudança e é imprescindível que a mudança ocorra na sua própria formação.

\section{THE COMPETENCE IN TECHNOLOGY FOR THE CLASSROOM: WHO LEARNS TO TEACH?}

Abstract: This work resumes one of the themes addressed in a PhD research, which sought to verify the proficiency profile acquired during the training of undergraduate students of the Biology, Physics and Chemistry degree courses of the Federal University of Rio Grande do Sul, in the use of Digital Information and Communication Technologies. These are disciplines that present difficulties to students due to their complexity. Thus, it is believed that the teacher who has the necessary competence in the use of those technologies can interact with the students in a technological environment, which is familiar and familiar to them. Some results of the empirical research done with the trainees are shown. The theoretical approaches deal with the necessary change of paradigms and attitudes in the scenario of teaching and learning in the 21 st century for the digital age in which we live.

Keywords: Technology in Education. Teacher Training. Educational Theories applied to Digital Technologies of Information and Communication.

\section{Referências}

LÉVY, P. Cibercultura. São Paulo: Editora 34, 1999.

LEVY, P. Só tablets não fazem trabalho sozinhos. [Entrevista cedida a] Bruno Alfano. Extra, Rio de Janeiro, 03 ago. 2014. Geral, p.15. Disponível em: $<$ https://extra.globo.com/noticias/educacao/educacao-360/so-tablets-nao-fazem-trabalhosozinhos-diz-filosofo-pierre-levy-13468681.html\#ixzz4Mon3TAZs>. Acesso em: 10 maio 2017.

LÉVY, P. Internet e escola de mãos dadas: entrevista com Pierre Lévy. Gestão Educacional, Curitiba, jul. 2012. Disponível em: <https://www.gestaoeducacional.com.br/internet-e-escolade-maos-dadas/>. Acesso em: 11 jul. 2018.

MORAES, R.; GALIAZZI, M. C. Análise textual discursiva. 2. ed. rev. reimpr. Ijuí: Unijuí, 2013.

MORAN, J.M. Educação híbrida: o futuro para a aprendizagem. [Entrevista cedida a] Andréa Antunes. São Paulo, 2015. [Blog de Palestras, Workshops, Cursos]. Disponível em: 
<https://moran10.blogspot.com/2015/08/educacao-hibrida-o-futuro-para.html >. Acesso em: 30 maio 2017.

MORAN, J.M. Principais diferenciais das escolas mais inovadoras. São Paulo, 2013. [Blog de Palestras, Workshops, Cursos]. Disponível em:

<https://moran10.blogspot.com/2015/12/os-diferenciais-das-escolas-e.html>. Acesso em: 11 jul. 2018.

MORAN, J.M. O uso das novas tecnologias da informação e da comunicação na EAD: uma leitura crítica dos meios. Belo Horizonte: [s.n.], 1999. [Palestra proferida pelo Professor José Manuel Moran no evento "Programa TV Escola - Capacitação de Gerentes", realizado pela COPEAD/SEED/MEC em Belo Horizonte e Fortaleza, no ano de 1999]. Disponível em: <http://portal.mec.gov.br/seed/arquivos/pdf/T6\%20TextoMoran.pdf>. Acesso em: 11 jul. 2018a.

MORAN, J.M. Ensino e aprendizagem inovadores com apoio de tecnologias. In: MORAN, J.M.; MASETTO, M. T.; BEHRENS, M.A. Novas tecnologias e mediação pedagógica. 21. Ed. rev. atual. São Paulo: Papirus, 2015a. p. 11-72.

PRENSKY, M. Nativos digitais, imigrantes digitais. On the Horizon, Bingley(UK), ano 9, n. 5, out. 2001. [Tradução de Roberta de Moraes Jesus de Souza]. Disponível em: <http://www.colegiongeracao.com.br/novageracao/2_intencoes/nativos.pdf $>$. Acesso em: 11 jul. 2018.

RIBEIRO, M.E.M. [Anotações da disciplina Tratamento de dados qualitativos por Análise Textual Discursiva]. Porto Alegre, 2018.

SIEMENS, G. Conectivismo: uma teoria de aprendizagem para a idade digital. [S.l.: s.n.], 2004. Disponível em: <http://usuarios.upf.br/ teixeira/livros/conectivismo\%5Bsiemens\%5D.pdf >. Acesso em: 24 abr.2017.

TECNOLOGIA e inovação em aula é tema de debate do Educação 360. O Globo, Rio de janeiro, 24 jan. 2016. Disponível em: <https://oglobo.globo.com/sociedade/educacao/educacao360/tecnologia-inovacao-em-aula-tema-de-debate-do-educacao-360-20167962 >. Acesso em: 24 abr. 2017.

UNESCO. Representação da UNESCO no Brasil. Aprendizagem móvel. Brasília, [201-?]. Disponível em: < http://www.unesco.org/new/pt/brasilia/communication-andinformation/access-to-knowledge/ict-in-education/mobile-learning/>. Acesso em: 12 maio 2017.

UNESCO. Representação da UNESCO no Brasil. Relatório de Monitoramento Global de EPT 2015 [Programa Educação para Todos 2015]. Brasília, [201-?]a. Disponível em:

<http://unesdoc.unesco.org/images/0023/002325/232565por.pdf>. Acesso em: 12 maio 2017a.

UNESCO. Representação da UNESCO no Brasil. TI na Educação do Brasil. Brasília, [201?]b. Disponível em: <http://www.unesco.org/new/pt/brasilia/communication-andinformation/access-to-knowledge/ict-in-education/>. Acesso em: 15 maio 2017b. 
UNIVERSIDADE Federal do Rio Grande do Sul. Projetos Pedagógicos de Cursos. Porto Alegre, 2016. Disponível em: <https://www1.ufrgs.br/intranet/portal>. Acesso em: 23 ago.2016. 